\title{
Translation Strategies of Culture-Loaded Words in Publicity Materials under the Background of "the Belt and Road"
}

Fei Liu

School of Foreign Languages, Shanxi Datong University, Datong, China

Email: feiexertion@163.com

How to cite this paper: Liu, F. (2019). Translation Strategies of Culture-Loaded Words in Publicity Materials under the Background of "the Belt and Road". Creative Education, 10, 839-847.

https://doi.org/10.4236/ce.2019.105062

Received: March 17, 2019

Accepted: May 7, 2019

Published: May 10, 2019

Copyright $\odot 2019$ by author(s) and Scientific Research Publishing Inc. This work is licensed under the Creative Commons Attribution International License (CC BY 4.0).

http://creativecommons.org/licenses/by/4.0/

\begin{abstract}
In order to translate Chinese culture accurately; let foreigners know more about China and let Chinese culture go to the world, based on the translation strategy of culture-loaded words in publicity materials under the background of "the Belt and Road", the translation principles of culture-loaded words in publicity materials are analyzed around three points. The first one is respecting the original culture; the second one is conforming to the cultural translation habits of other ethnic groups, and the last one is conforming to different national language thinking. Based on these points, the translation strategies of culture-loaded words in publicity materials are explored. It is found that many translation methods can be used for the translation of culturally loaded words, such as literal translation with annotation, transliteration plus notes, free translation, and ellipsis intranslation. These methods provide effective translation strategies for the translator's translation practice. If these methods can be used flexibly according to the situation, they can help the translator to complete the translation task well, and enable foreigners to better understand Chinese culture. Therefore, Chinese culture can be disseminated around the world, and China's international influence can be enhanced.
\end{abstract}

\section{Keywords}

The Belt and Road, Publicity Materials, Chinese Culture-Loaded Words, Language Thinking

\section{Introduction}

With the improvement of China's comprehensive national strength, international status and international influence, what happened in China has been and 
is being closely watched by the international community. With the implementation of the strategy of "Chinese Culture Going Out" and the development of external communication, China's external communication has made gratifying achievements. However, misunderstandings and prejudices still exist in the international community, especially in the western countries. One-sided, untrue and even distorted reports and misreading of China's policy intentions are still serious. Although ideological differences and contradictions are important factors in the emergence of such obstacles, it is an indisputable fact that most westerners are not familiar with Chinese language and culture, do not understand China's history and current situation, and do not correctly interpret China's policies and propositions. Therefore, it is a long-term, arduous and challenging task to explain and introduce China to the world.

"The Belt and Road" refers to the abbreviation of "Silk Road Economic Belt" and "twenty-first Century Maritime Silk Road". In September and October 2013, Chinese President $\mathrm{Xi}$ Jinping proposed the cooperative initiatives for the construction of the "New Silk Road Economic Belt" and the "Marine Silk Road of the 21st Century". It will fully rely on the existing bilateral and multilateral mechanisms between China and the countries concerned, with the help of existing and effective regional cooperation platforms (Wang, Wang, \& Zhang, 2018). In other words, China's economic and trade targets are increasing; interconnection is advancing rapidly, and trade exchanges are increasing. The Belt and Road can help China digest excess capacity. Secondly, China should not always make such low-end industries like shoes, socks and shirts. The overall export level should be improved and China's industrial chain should be upgraded. Moreover, helping countries along the way to build infrastructure still requires money and Chinese construction team (Du \& Ren, 2018). At the same time, it can also facilitate Chinese travel and trade. It can bring a big increase to Chinese overall income. Under the background of "the Belt and Road", the communication between China and other countries is more and more close, and the importance of translation is gradually emerging.

In national communication and cooperation, translation is not only for a language, but also a means to spread culture and promote the harmonious development of the country. Language, as the carrier of culture, is the characteristic of a country and has its own cultural content with unique national characteristics. However, in the actual translation process, it is found that the corresponding vocabulary cannot be found. How to accurately translate Chinese language and culture and improve the influence of Chinese culture is the problem people are facing.

Publicity materials, as the name implies, refer to materials used for external publicity. The forms of publicity include books, periodicals, newspapers, radio, television, Internet and other media, as well as international conferences ( $\mathrm{Lv}$, 2018). By using various means of communication, Chinese culture will be disseminated so that foreigners can better understand China's past, present and future development. That is to say, to let China go to the world and let the world know China. Therefore, the translation of publicity materials plays an indis- 
pensable role as a bridge to enhance the international community's understanding and cooperation with China, to establish a good international image of China, and to create a good external environment for national development. Publicity translation is a kind of facade work, in which errors and defects will be magnified. It is no exaggeration to say that publicity translation is a concrete reflection of a country's level of foreign exchange and the construction of its humanistic environment. To a large extent, the effectiveness of translation should be reflected in the effectiveness of publicity translation. In the translation of publicity materials, say, various kinds of foreign propaganda materials (such as government work reports, white papers and other government documents, local foreign propaganda reports, foreign propaganda brochures, exhibition materials and signs in public places, etc.), errors or irregularities can be found everywhere, and the quality of translation is worrying. Unqualified or incorrect translations not only fail to achieve the purpose of publicity and information, but also easily lead to confusion and misleading, directly affect China's external image, and have far-reaching and irreparable negative effects. Hence, the translation strategies of publicity materials under the background of "the Belt and Road" need to be explored.

\section{Literature Review}

Culture-loaded words refer to words, phrases or idioms used to express something unique to a culture. These words reflect that in the long history, each ethnic group gradually accumulates a unique way of activity different from other ethnic groups. In addition, there is another way of defining culture-loaded words, that is, culture-loaded words, also known as vocabulary vacancies, refer to the cultural information contained in the source language vocabulary cannot find the corresponding word in the target language ( $\mathrm{Yu}, 2018$ ). Therefore, culture-loaded words refer to those words, phrases or phrases that contain certain cultural information, and it is usually difficult to find the corresponding words in the target language, nonetheless, which is a staple part in publicity materials.

Nida believes that, for translation, it is even more important to master two cultures than to master two languages. Language is not only a tool used by human beings to express ideas, feelings and exchanges, but also a carrier of culture. People with different languages have different ways of thinking and expression. Therefore, cultural differences inevitably occur in different languages, which leads to the emergence of culture-loaded words. Due to the different geographical and humanistic environments in the long-term life and practice of different nationalities, different lifestyles, ideologies, religious beliefs and artistic forms have been formed, which leads to the essential differences between eastern and western traditional cultures, and thus makes translation difficult to some extent (Qian, 2019). In addition, different cultural backgrounds make the cultural-loaded vocabulary of English and Chinese conflict with each other, which naturally leads to vocabulary vacancies.

Scincr, a famous translation theorist, points out that "human commonness makes translation possible". Translatability and untranslatability are of vital im- 
portance for each school of translation to establish its principles and whether it can become an independent discipline. Essentially, denying the translatability of translation denies that language has the ability to express the unknown. In addition, untranslatability equals unknowable, so untranslatability is mainly due to the limited ability of the translator himself. Obviously, only by recognizing the translatability of culture-loaded words can people effectively communicate with the target language readers and achieve the purpose of publicity.

In 2013, Zhu Lingyan pointed out the importance of culture-loaded words in the process of publicity, introduced the translation strategies of culture-loaded words, elaborated on the specific methods adopted in the process of translation, and concluded that the translation of culture-loaded words should be based on foreignization strategy and planning translation as auxiliary strategy (Tabasinezhad, Mahboudi, Wenzel et al., 2019). In 2016, Luo Xueqing sorted out and classified the cultural-loaded words which caused obstacles to the translator through case studies. Guided by Skopostheorie, according to the characteristics of different cultural words, corresponding strategies are put forward, including literal translation, literal translation with necessary interpretation and connotation translation (Dubuc, Pieters, van der Linden et al., 2019). Luo Xueqing believes that the primary goal of translators should be to achieve the purpose of translation activities, rather than to translate the original content word for word into the target language. On the premise of achieving the purpose of the activity, the translator should also ensure the quality of the translation, respect the content of the original text and not play at will (Naveed, Waqas, Memon, Jabeen, \& Sheikh, 2019). In 2017, guided by the interpretive theory of interpretive school and the interpretation mode theory of "three party two language communication system", Chen Maochun studied the explicit translation strategies of culture loaded words in Chinese English media interpretation under the background of "the Belt and Road". In 2017, Yi Xinqi explored the translation of culture-loaded words in tourism publicity translation from the perspective of cultural translation theory, and put forward three principles of cultural adaptability that should be followed in the translation of Chinese culture-loaded words (Mathias, Klingebiel, Hartwigsen, Sureth, Macedonia, Mayer, \& von Kriegstein, 2019). They are the principles of semantic cultural adaptability, pragmatic cultural adaptability and aesthetic cultural adaptability (Liu, 2015). In 2017, Liang Sen, guided by skopostheorie, a German functionalist theory, mainly analyzed the English translation of culture-loaded words in government work reports, and then proposed skopostheorie-guided translation strategies, foreignization strategies and domestication strategies to improve the translation quality of news texts. In 2017, guided by the theory of translation ecology, Chen Zhihai et al. studied the influence of natural environment, social environment, normative environment and translator's physiological and psychological environment on the translation of culture-loaded words through analyzing some examples of translation of culture-loaded words in literary works (Liu \& Meng, 2018). The best ecological balance between the original author and the target language readers is tried to 
find out. The application of theory in the translation practice of culture-loaded words is not only a new breakthrough in the study of culture-loaded words translation, but also a new integration and development of translation ecology. In 2018, Kim Y et al. proposed simple but effective methods to improve word-by-word translation of cross-lingual embeddings, using only monolingual corpora but without any back-translation. A language model for context-aware search is integrated, and a novel denoising autoencoder is used to handle reordering (Kim, Geng, \& Ney, 2018).

Based on the study of the culture loaded words in the publicity materials under the background of "the Belt and Road", the translation principles of culture loaded words in the publicity materials are analyzed around the three points. They are respecting the original culture, conforming to the translation habits of other ethnic cultures, and conforming to the linguistic thinking of different ethnic groups. Moreover, through the study, specific translation strategies of culture-loaded words are put forward, which is of great significance for translators to complete translation tasks, foreigners to better understand Chinese culture, and to improve China's international influence.

\section{Translation Principles of Culture-Loaded Words in Publicity Materials}

In the process of cultural development, language is not only the carrier of cultural promotion, but also the main way to reflect cultural information. The application of culture-loaded words in national exchanges and cooperation can highlight the traditional Chinese culture and national characteristics, which is of great significance. In the translation work, the translation of two languages is of great significance. It requires staff to master two different cultures in order to better translate various languages and present the culture in the language. Foreign publicity is the main way for a country to establish its image and disseminate its traditional culture. Publicity materials should be translated according to different ways of understanding in different countries. It is a better understanding of Chinese culture for foreign people. In translating publicity materials, attention should be paid to several points as follows:

\subsection{Respect for the Original Culture}

When translating publicity materials, the original Chinese culture in the text information should be retained. The main purpose of publicity materials is to propagate Chinese culture, to transmit Chinese culture to other countries, and to increase the influence of Chinese culture. Therefore, in the process of translation, the Chinese cultural content should be retained, and the text information in the culture-loaded words should be transmitted to the outside world, to realize the role of publicity materials and improve the national influence.

\subsection{Accord with the Translation Habits of Other Ethnic Cultures}

In the process of translating publicity materials, the materials should be trans- 
lated according to the expression of the translated language, to ensure that the foreigners can understand them. There are many idioms and legends in the broad spirit of Chinese culture. If Chinese thinking is used in translating, it will affect the effect and quality of translation. Therefore, in practice, different language expressions should be combined to translate publicity materials, to accurately convey Chinese information.

\subsection{Consistent with Language Thinking of Different Nationalities}

When translating publicity materials, it is not only necessary to use different expressions in different languages, but also to incorporate the thinking and cultural patterns of different countries into the translation process and translate culture-loaded words into languages suitable for the communication of other nationalities, to realize the significance of publicity and lay a foundation for the development of Chinese culture.

\section{Translation Strategies of Culturally Loaded Words in Publicity Materials under the Background of "the Belt and Road"}

Under the background of "the Belt and Road", the exchanges between China and other countries in the world have gradually increased. In order to promote the development of Chinese culture and enhance the international influence of Chinese culture, importance should be attached to the way of translating culture-loaded words in publicity materials, to ensure the accurate expression of Chinese culture and build good communication and cooperation.

\subsection{Transliteration plus Annotation}

Transliteration plus annotation means adding explanatory annotations after translation in order to make them understood by foreign people. In Chinese culture-loaded words, some words cannot be expressed accurately in English. In order to express them accurately in the actual translation process, transliteration plus annotation method can be used to improve the accuracy and scientificity of translation. In the process of transliteration and annotation, there are many ways to supplement, such as background culture, source of words and so on. In this way, the translation can be better understood by the foreign people.

For example, the 13th Five-Year Plan from 2016 through 2020 can be translated into the translation of the main objectives, tasks and major initiatives of the 13th Five-Year Plan form. The 13th Five-Year Plan is an important period for the construction of a well-off society in an all-round way, which means the period from 2016 to 2020. In the process of translation, translating the hidden time can help foreign audiences understand better.

\subsection{Literal Translation with Notes}

Literal translation plus annotation means direct translation according to literal 
meaning. The cultural characteristics contained in it can be translated by annotation in order to be understood by foreigners. In this way, the problem of misunderstanding in translation can be avoided and the difference between the two cultures can be made up for. For example, at a meeting of the general secretary, the following sentence is mentioned: Should we continue to lead the world and create a better future, or should we slow down and wait to be surpassed? Is it deepening the process of integration or falling into a fragmentation whirlpool? Is it the practice of openness, inclusiveness and the common initiation of the Asia-Pacific century, or is the body entering the 21 st century while the thinking mode remains in the past? This is how it is translated into English, "Shall we continue to lead the world in creating a bright future, or shall we slow down only to be outperformed by others? Shall we deepen the integration process, or shall we let ourselves slip into a vortex of fragmentation? Shall we embrace openness and inclusiveness to work together for an Asia-Pacific century, or shall we cling to an outdated mindset until for the 21 st century?". In the process of translation, the translation of this sentence falls into fragmentation whirlpool mainly adopts literal translation. In this way, foreigners can better understand and spread Chinese culture.

\subsection{Free Translation}

Free translation is to translate the text according to the content of the publicity materials. Transliteration is different from transliteration and literal translation. It does not need to translate sentence by sentence in the process of translation. It only needs to express the meaning of the content of the text, and the translation requirements are low. In the APEC leaders' informal meeting, there is a sentence: Jointly face global challenges. In the post-international financial crisis period, we should not only grasp the core of economic growth and strengthen macro-policy coordination, but also properly deal with global issues such as epidemic diseases, food security, energy security. The translation into English is as follows: "Together, we should face the global challenges. In the post-globaleconomic-crisis era, we need, on one hand, to treat economic growth as our core task, while strengthening macro policy support; and on the other hand, to properly handle global issues such as epidemic diseases, food safety, and energy security". This sentence is translated by means of free translation. Expressing the content of the text in a free translation way can improve the preparation of expressing the content and promote the development of Chinese. Free translation is a good translation strategy to achieve cultural translation, communication and integration. However, in translation practice, translators should flexibly apply this translation principle to play the necessary complementary and regulatory role of domesticated translation. Finally, the rationality of the micro-cultural concept of free translation is further demonstrated from the perspective of the latent text theory of language. Firstly, free translation can retain the explicit and latent texts of the micro-culture of the original text to the greatest extent, which is conducive to retaining the authentic intention of the author of the original 
text. Secondly, the improvement of free translation needs the trust of target readers. Thirdly, latent text is an important defamiliarization technique in literary texts. Therefore, translators should try their best to retain the latent text in the source text and reproduce the defamiliarization technique of the original text by means of free translation.

\subsection{Ellipsis in Translation}

Ellipsis refers to the fact that in translation, some words in the original text can be omitted without being translated. Although there is no such word in the translated text, it already has the meaning expressed by the word in the original text, or the meaning of the word in the translated text is self-evident. The purpose of ellipsis is to make the translation smoother and more in line with the translation habits. However, it should be noted that ellipsis does not delete some of the ideological content of the original text, and ellipsis cannot change the meaning of the original text.

In the context of the "the Belt and Road" approach, the omission translation method can be used to translate the text content in the translation of publicity materials. The broad spirit of Chinese culture makes it very difficult for foreigners to understand Chinese culture. When translating, this part of the content can be abandoned. In this way, the Chinese language and culture not only can be accurately transmitted, but also can be expressed in another language thinking, which is conducive to the cooperation and development of various countries.

\section{Conclusion}

All in all, in the context of the "the Belt and Road" road, the exchanges of China with other countries in the world have gradually increased. In order to spread Chinese culture and enhance China's international influence, importance should be attached to the translation of the culture-loaded words in publicity materials, and appropriate translation methods combined with the characteristics of different languages should be developed, to achieve the role of publicity materials and lay the foundation for national development.

\section{Acknowledgements}

This research was supported by Youth Scientific Research Project of Shanxi Datong University (Project No. 2015Q27) and Scientific Research Project of Shanxi Datong University (Project No. 2018K27).

\section{Conflicts of Interest}

The author declares no conflicts of interest regarding the publication of this paper.

\section{References}

Du, Y. M., \& Ren, H. (2018). Study of the Translation Strategies of Chinese Culture-Loaded Words under Skopos Theory a Case Study of Xi Jinping's Report at the 
19th CPC National Congress. In I. Solovjeva, Y. Zhang, R. Green, \& M. Zhang (Eds.), Proceedings of the International Conference on Contemporary Education, Social Sciences and Ecological Studies (CESSES 2018) (Vol. 283). Paris: Atlantis Press. https://doi.org/10.2991/cesses-18.2018.128

Dubuc, E., Pieters, P. A., van der Linden, A. J., van Hest, J. C. M., Huck, W. T. S., \& de Greef, T. F. A. (2019). Cell-Free Microcompartmentalised Transcription-Translation for the Prototyping of Synthetic Communication Networks. Current Opinion in Biotechnology, 58, 72-80. https://doi.org/10.1016/j.copbio.2018.10.006

Kim, Y., Geng, J., \& Ney, H. (2018). Improving Unsupervised Word-by-Word Translation with Language Model and Denoising Autoencoder. In Proceedings of the 2018 Conference on Empirical Methods in Natural Language Processing (pp. 862-868). Brussels: Association for Computational Linguistics.

Liu, W. D. (2015). Scientific Understanding of the Belt and Road Initiative of China and Related Research Themes. Progress in Geography, 34, 538-544.

Liu, W. T., \& Meng, H. M. (2018). A Study on English Translation of Culture-Loaded Words in Tourism Texts from the Perspective of Eco-Translatology. Studies in Literature and Language, 17, 105-108.

Lv, Y. P. (2018). Research on CE Translation Techniques of Culture-Loaded Expressions. In I. Solovjeva, Y. Zhang, R. Green, \& M. Zhang (Eds.), Proceedings of the International Conference on Contemporary Education, Social Sciences and Ecological Studies (CESSES 2018) (Vol. 283). Paris: Atlantis Press. https://doi.org/10.2991/cesses-18.2018.120

Mathias, B., Klingebiel, A., Hartwigsen, G., Sureth, L., Macedonia, M., Mayer, K., \& von Kriegstein, K. (2019). Sensorimotor Cortices Casually Contribute to Auditory Foreign Language Vocabulary Translation Following Multisensory Learning. Brain Stimulation, 12, 401-402. https://doi.org/10.1016/j.brs.2018.12.295

Naveed, S., Waqas, A., Memon, A. R., Jabeen, M., \& Sheikh, M. H. (2019). Cross-Cultural Validation of the Urdu Translation of the Patient Health Questionnaire for Adolescents among Children and Adolescents at a Pakistani School. Public Health, 168, 59-66. https://doi.org/10.1016/j.puhe.2018.11.022

Qian, Y. X. (2019). A Quantitative Study on the Translation Strategy of Material Culture-Loaded Words in the Story of Stone by David Hawkes. Journal of Literature and Art Studies, 9, 87-95. https://doi.org/10.17265/2159-5836/2019.01.009

Tabasinezhad, M., Mahboudi, F., Wenzel, W., Rahimi, H., Walther, T. H., Blattner, C., \& Omidinia, E. (2019). The Transient Production of Anti-TNF- $\alpha$ Antibody Adalimumab and a Comparison of Its Characterization to the Biosimilar Cinorra. Protein Expression and Purification, 155, 59-65. https://doi.org/10.1016/j.pep.2018.11.006

Wang, H., Wang, H. C., \& Zhang, S. (2018). Pragmatics Pattern of Translating Lingnam Culture-Loaded Words and Phrases-Taking English Periodicals of the First Half of 19th Century in China as an Example. International Journal of Language and Linguistics, 6, 154-162. https://doi.org/10.11648/j.ijll.20180605.13

Yu, J. Y. (2018). Research on the Omission of Culture-Loaded Words in Fu Sheng Liu Ji (Lin Yutang's English Version) from the Perspective of Functional Equivalence. Modern Linguistics, 6, 8-13. https://doi.org/10.12677/ML.2018.61002 